\title{
Redes e teias na gestão compartilhada dos consórcios operacionais de empresas de ônibus de Porto Alegre
}

\author{
Nets and webs in the shared management of bus companies in Porto Alegre - \\ Brasil
}

Luiz Augusto Bichara ${ }^{1}$

Élvia Fadul ${ }^{2}$

\section{Resumo}

Este artigo tem como objetivo analisar os consórcios de operação formados por empresas prestadoras de serviço público de transporte de passageiros por ônibus no município de Porto Alegre, na década de 1990. 0 estudo se propõe a investigar se os benefícios assegurados pelo modelo de organizações em rede podem ser estendidos a esses consórcios gaúchos. Buscou-se, também, caracterizar a estrutura de organização e entender o seu processo de formação. A pesquisa se desenvolveu com base em fontes secundárias e a partir de entrevistas com informantes-chave do sistema de transporte local, empresários consorciados, gestores públicos e representantes dos trabalhadores do setor. 0 estudo mostra que a experiência dos consórcios gaúchos apresenta resultados interessantes, sobretudo, nos seus aspectos institucionais e de negociação. Entretanto, o modelo se traduz, apenas, numa representação imatura ou incompleta do modelo de organizações em rede, não estando pronto para usufruir todas as suas vantagens, inclusive, no que tange da sua continuidade.

Palavras-chave: Redes Organizacionais - Consórcios de Empresas de Ônibus - Políticas de Transportes Urbanos

\begin{abstract}
The objective of this paper is to analyze operating consortium formed by bus companies in the Porto Alegre district area. The study aimed at investigating whether benefits yielded by the network organization model are to be extended to the State of Rio Grande do Sul ("gaucho") consortia. A secondary aim was characterizing its organizational structure, learning about its formation process and identifying which changes it might have caused in public transportation in Porto Alegre. Research was developed on the basis of secondary sources and on interviews carried out with key informants from local transport system consortium partners, public managers and the sector's work representatives. Gaucho consortia experience can be seen as very productive, especially in terms of its managerial and institutional aspects, although its model can be described simply as an immature and incomplete representation of the network organizational model, and, as though, not yet ready to absorb all of its advantages, especially as regards maintainability.
\end{abstract}

Keywords: Organizational Network; Bus Company Consortium; Public Transportation Policies

\footnotetext{
1 Mestre em Administração - UFBA. Professor na NPGA-UFBA. Endereço:- Av. Tancredo Neves, 1632, Edf. Salvador Trade Center, Torre Norte, Salas 1916/1917 Caminho das Árvores - Salvador - Ba - Brasil - CEP: 41820-020. E-mail: luiz.bichara@globalsmart.com.br

2 Doutorado em Urbanisme. - Université Paris XII - Institut d'Urbanisme de Paris. Coordenadora do Programa de Pós-Graduação em Administração PPGA/UNIFACS - Rua Dr. José Peroba, 251 s/601 - Stiep - Salvador - Bahia - CEP: 41.770-235. E-mail: madm@unifacs.br e/ou elvia@ufba.br 


\section{Introdução}

O setor de transporte público de passageiros no Brasil enfrenta uma crise aguda, ampliada pelos patamares elevados de custo que o serviço vem atingindo. Não há mais subsídios do governo às tarifas, que ficam inacessíveis para grande parcela da população, praticamente, excluída desse serviço, comprometendo sua mobilidade e cerceando o seu direito à cidadania.

A ausência de uma política nacional consistente para o transporte urbano de passageiros vem estimulando a valorização excessiva de experiências locais, aparentemente bem-sucedidas, que terminam sendo amplamente divulgadas e adotadas com extrema rapidez, sem que haja uma avaliação mais rigorosa sobre a eficácia e a durabilidade de seus resultados. Recursos financeiros expressivos e esforços concentrados terminam sendo investidos na implantação de projetos que, mais adiante, fracassam ou não geram os resultados esperados.

Na ausência de uma atuação mais efetiva do governo federal, prefeituras e empresários de ônibus buscam alternativas, e uma delas é a formação de consórcios de operação ou a gestão compartilhada de empresas privadas de transporte público de passageiros. Esse novo modelo de organização da operação do transporte urbano de passageiros surgiu oficialmente em Porto Alegre em 1992, sob a justificativa de que, através da unificação da operação do transporte por ônibus, seria possível aumentar a competitividade do segmento formal de transportes e contribuir para a sobrevivência das empresas do setor.

Mesmo não conhecendo o alcance dessas medidas, se elas de fato podem ajudar na superação da crise, muitas cidades vêm adotando o modelo, indicando a necessidade de uma avaliação mais profunda da experiência, pretensão que aqui apenas se inicia. A importância do tema encontra-se não apenas na necessidade de compreender melhor o modelo para fornecer insumos à tomada de decisão pelos gestores e empresários, mas também na possibilidade de participar desse processo de discussão das alternativas para solução do problema do setor de transportes urbanos no país.

Para a realização deste estudo foi construída uma matriz de indicadores de avaliação composta por dois macrogrupos: os indicadores de avaliação de desempenho interno, que se destinam a avaliar os resultados da formação dos consórcios para o grupo de empresas consorciadas; e os de desempenho externo, relativos aos resultados gerados para os usuários/clientes do serviço e empregados do setor. Ao grupo dos indicadores voltados à avaliação do desempenho interno foram associados três enfoques, o financeiro, cujos impactos se refletem nos resultados de faturamento, remuneração e resultados contábeis em geral; o econômico, com impactos na produtividade dos fatores e itens de custos vinculados à produção dos serviços; e o estratégico, associado aos atributos determinantes das organizações em rede que, em conjunto, contribuem para a durabilidade dos demais resultados, refletido na mudança do padrão das relações institucionais entre as operadoras, órgão gestor e clientes e nos resultados em termos do market share sobre o mercado de transportes da Grande Porto Alegre. Com relação ao grupo dos indicadores de avaliação do desempenho externo, os enfoques são os de mudança no padrão de qualidade sentido pelos clientes, dos resultados econômicos sobre a tarifa cobrada pelo serviço e na transferência de parte dos ganhos aos trabalhadores do setor. Dentro dos diversos enfoques, e sempre que era procedente a vinculação, buscou-se identificar os resultados sobre cada associada ao consórcio (individuais), os resultados conseguidos pelo consórcio (coletivo) e os resultados para órgão gestor, clientes e trabalhadores (externos).

Assim, este artigo volta-se para o estudo da formação estruturada de consórcios de operação constituídos por empresas operadoras privadas através da análise do caso de Porto Alegre. Não se pretende, aqui, esgotar todos os enfoques que o tema pode propiciar, mas abordá-lo sob sua ótica organizacional conceitual, avaliando a proximidade desse arranjo organizacional com o modelo de organizações em rede e se os benefícios assegurados por esse modelo podem ser estendidos aos consórcios de empresas de ônibus.

O estudo inicia com a descrição das principais características e atributos essenciais na formação de redes e consórcios, assim como das formas de avaliação de seus resultados, fornecendo uma visão geral do surgimento do modelo de operação consorciada no contexto do transporte urbano de passageiros do país. Em seguida, 
caracteriza o processo de formação e a evolução dos consórcios gaúchos para, por fim, identificar as semelhanças entre os consórcios e as organizações em rede, de modo geral.

\section{As redes, uma nova forma de organização}

As organizações em rede fazem parte do conjunto de novos arranjos organizacionais que se consolidaram no final do século XX, traduzindo um desejo das empresas de ampliarem a sua competitividade e garantirem a sua sobrevivência, num mercado cada vez mais global e complexo. Embora a forma de organização em redes tenha existido em outras épocas, é a partir da década de 1980 que ela ganha impulso, integrando um cenário de mudanças globais das relações sociais e econômicas envolvendo o Estado, a sociedade, as organizações e demais instituições. É um momento de profunda reestruturação do capitalismo, no qual se registra, além da descentralização das empresas e sua organização em redes, uma maior flexibilidade no seu gerenciamento; o fortalecimento do papel do capital vis-à-vis ao trabalho, com a redução do poder dos movimentos sindicais; a individualização e diversificação crescente das relações de trabalho; a ampliação da participação das mulheres na força de trabalho, ainda que em condições discriminatórias; a atuação do Estado na desregulamentação dos mercados, variando a intensidade de região para região, desfazendo a atuação do Estado do bem-estar social; e finalmente, o aumento da competição econômica global para acumulação e gestão de capital.

A retirada do Estado da economia e de muitas funções sociais pressupõe que outras forças privadas assumirão os papéis ou a humanidade será tomada pelo caos. O pressuposto é o de que organizações espontâneas possam assumir os papéis. Será a era das tribos ou de grupos: grupos de pessoas, grupos de empresas etc. (CASAROTTO FILHO \& PIRES, 1999, p.19).

Castells (1999) acredita que a tecnologia da informação não tenha determinado essa nova sociedade e cultura em formação, mas forneceu o instrumental para essa transformação. Esse novo paradigma se caracteriza pela existência de um espaço de fluxos, de uma intemporalidade e pelo forte incentivo à formação de uma sociedade globalizada e centrada no uso e na aplicação da informação e divisão do trabalho segundo um padrão complexo de redes interligadas.

O fator decisivo desse processo foi a criação da Internet na década de 1960. O modelo daí derivado foi o de uma arquitetura em rede onde não há controle central e sua composição dá margem à conexão de milhares de redes com variadas formas de acesso.

Deve ser ressaltado que conceitos como produtividade e competitividade de unidades ou agentes também começam a ser avaliados sob outra ótica nessa nova economia, pois passam a depender da capacidade destes de gerar, processar e aplicar, de forma eficiente, a informação baseada em conhecimento. Esses processos, entretanto, levaram a arranjos variáveis, em diferentes contextos culturais e institucionais, através da combinação entre tecnologia e produtividade, na busca por maior lucratividade pelas empresas.

De fato, no contexto da reestruturação econômica dos anos 1980, várias estratégias reorganizacionais foram adotadas pelas empresas ou ganharam impulso, seguindo certos princípios da economia informacional descrita por Castells. Alguns autores, inclusive, apresentam interpretações divergentes sobre esse fenômeno de reestruturação econômica, social e organizacional, iniciado nos anos 1980, posterior à crise econômica da década de 1970, e que poderiam ser sintetizadas em três posições conceituais importantes:

- as estratégias empresariais decorreram da exaustão do sistema de produção em massa, determinando uma segunda divisão industrial na história do capitalismo;

- os novos arranjos organizacionais representaram uma resposta à crise de lucratividade do processo de acumulação de capital;

- as mudanças nas estruturas organizacionais traduziram-se numa evolução de longo prazo do "fordismo" e do "pós-fordismo" (produção e produtividade $x$ consumo e concorrência). 
Apesar dessa divergência de avaliação pelos analistas quanto aos fatores que determinaram essa nova ordem mundial a partir da década de 1980, observa-se que há certa convergência em alguns aspectos identificados:

- da década de 1970 em diante houve uma divisão importante na organização da produção e dos mercados na economia global;

- as mudanças nas organizações tiveram alguma interação com os avanços da tecnologia da informação, embora fossem independentes. Exceção feita às empresas comerciais onde as mudanças se deram em fase anterior à de difusão da tecnologia de informação;

- o elemento impulsionador das mudanças organizacionais era a necessidade de se adotar maior flexibilidade na produção, gerenciamento e marketing, para conviver com a incerteza gerada pelo ritmo acelerado das mudanças no ambiente econômico, institucional e tecnológico da empresa; e

- a adoção do modelo da produção enxuta para reduzir custos com mão-de-obra, através da automação de atividades, eliminação de tarefas e supressão de camadas administrativas, foi a responsável por muitas das mudanças organizacionais que visavam reduzir os processos de trabalho e as práticas de emprego.

No caso do Brasil, esses processos foram intensificados a partir de 1994, quando se passou a trabalhar com o ambiente de economia estabilizada, diminuindo o grau de liberdade dos ganhos financeiros e restringindo-se o alcance de competitividade às atividades fim da empresa. Mas, independente do peso da influência dos fatores tecnológicos, observa-se a partir da crise dos anos 1970, quando as grandes empresas industriais sentiram uma retração na demanda por produtos padronizados e despersonalizados, o aparecimento de novas trajetórias organizacionais que perseguem o aumento da produtividade e da competitividade, em face das novas características mercadológicas impostas pelo paradigma tecnológico e pela nova economia global:

- transição da produção em massa para a produção flexível, ou do "fordismo" ao "pós-fordismo", que significa o abandono dos ganhos de produtividade pela economia de escala tendo como base o controle de um grande mercado e uma produção mecanizada e padronizada, desenvolvida à luz de uma grande empresa integrada verticalmente e operando sob condições rígidas de divisão social e técnica do trabalho;

- a crise da grande empresa e a formação de parcerias para potencializar a flexibilidade das pequenas e médias como agentes de inovação e fontes de geração de empregos, ainda mantendo-as sob o seu controle;

- a adoção de novos métodos de gerenciamento, sobretudo daqueles herdados da cultura japonesa ("toyotismo"), cujos elementos básicos são o sistema de fornecimento kan-ban (ou just in time), o controle de qualidade total, o envolvimento de trabalhadores no processo de produção através de incentivos aos trabalhos em equipe, a descentralização da decisão, os esquemas de recompensa e a estrutura de organização horizontal. Outro aspecto importante desse modelo é a estabilidade e complementaridade no relacionamento entre empresa e rede de fornecedores;

- a formação de alianças corporativas estratégicas; ou seja, a interligação de empresas de grande porte com objetivos específicos em relação a períodos, mercados, produtos e processos, não eliminando a concorrência, como ocorre nos acordos de cartéis ou de oligopólios;

- finalmente, a formação de redes entre empresas, que podem ser multidirecionais pela conexão entre empresas de pequeno e médio porte para exploração de determinado nicho de mercado ou empreendimentos cooperativos, ou se traduzirem no licenciamento ou subcontratação de produção sob o controle de uma grande empresa.

A formação de redes, referência teórica deste artigo, na visão de Castells, veio atender à necessidade de maior flexibilidade da produção, mas não solucionou o problema de adaptabilidade da empresa participante que, para 
absorver os benefícios da rede, também teve que se tornar uma rede, assumindo uma horizontalidade estrutural através da descentralização da tomada de decisões, da ampliação da autonomia e da absorção do conceito de unidades integradas de negócios.

A formação de novos arranjos e estruturas organizacionais baseadas na colaboração e na cooperação entre empresas significou uma alternativa para aquelas organizações que se sentiam isoladas e incapazes de acompanhar a dinâmica concorrencial. Entre as pequenas e médias empresas, esses arranjos surgiram timidamente sob a forma de parcerias, centrais de compras, formação de redes de cooperação e colaboração e, em alguns casos, no desenvolvimento de clusters de empresas onde a cooperação e a competição acontecem simultaneamente.

As redes de empresas (networks) e os aglomerados empresariais se traduzem em alternativas viáveis e, muitas vezes, necessárias, não apenas para a sobrevivência das pequenas empresas - visto que o isolamento as torna incapazes de acompanhar o ritmo de mudanças e as exigências de atualização tecnológica e gerencial -, mas também para a adaptação à dinâmica dos mercados e obtenção dos ganhos de escala necessários à competição, a custos extremamente menores em virtude da cooperação e da diluição do risco "Nessa nova ótica, a empresa não necessita ter de fazer uma escolha estratégica única entre liderança de custos ou diferenciação, como afirma Porter, mas pode garantir vantagens competitivas oriundas de ambas as opções estratégicas por ele propostas" (CASAROTTO FILHO \& PIRES,1999, p.29).

São condições essenciais à formação de redes, na visão de Alter e Hage (1993): o desejo de cooperar de seus participantes, a necessidade de buscar competências específicas, a necessidade de recursos financeiros, a definição conjunta de objetivos próprios de cada organização e da rede como um todo, a expectativa de divisão de riscos e de eficiência adaptativa, bem como a existência de cultura de confiança entre os futuros parceiros.

Castells define uma empresa em rede como aquela forma específica de empresa cujo sistema de meios é constituído pela interseção de segmentos autônomos de objetivos (CASTELLS, 1999, p.191). Essa autonomia dos componentes da rede convive, entretanto, com a própria dependência em relação à rede e a fragmentação, se considerarmos que esses componentes também podem pertencer a outras redes. $\mathrm{O}$ desempenho da rede, nesse sentido, dependerá da sua capacidade estrutural de facilitar a comunicação sem ruídos entre seus componentes (conectividade) e do nível de aderência entre os objetivos individuais e os da rede como um todo (coerência).

Outros autores apresentam conceitos diferenciados para as organizações em rede. Podolny e Page (1998) a vêem como uma coleção de atores que mantêm relações de troca duráveis e repetidas uns com os outros e, ao mesmo tempo, sem uma autoridade organizacional legítima para arbitrar e resolver disputas que surgem durante as trocas. Para Geglie e Dini (1999), redes são grupos de firmas que cooperam no desenvolvimento conjunto de um projeto, complementando-se umas às outras e especializando-se para superar problemas comuns, adquirir eficiência coletiva e entrar em novos mercados. Para Grandori \& Soda (1995) a rede é a formação de relações interorganizacionais, segundo uma perspectiva econômica e mercadológica, com o fim de maior definição e de uma participação mais competitiva de cada uma das empresas denominadas nós. Thorelli (1986) entende a rede como uma forma de organização intermediária ou híbrida que é definida segundo parâmetros de coordenação e cooperação, sob os quais se busca maior competitividade nos mercados de atuação para as empresas nela inseridas.

As redes de empresas podem apresentar diversas configurações, mas podem ser agrupadas em duas categorias específicas, de acordo com as relações estruturais existentes entre as empresas que a compõem:

a) redes verticais ou top-down - que se caracterizam pela colaboração entre empresas com produtos complementares ou em fases diferentes de uma mesma cadeia produtiva, compartilhando recursos e informações e reduzindo riscos e incertezas. Geralmente, derivam de empresas maiores que subcontratam pequenas empresas que atuam como suas fornecedoras, mantendo uma relação de dependência ou de subordinação (franquias); e 
b) redes horizontais - que se caracterizam pela colaboração entre empresas que atuam na mesma fase de uma cadeia produtiva, realizando, em conjunto, atividades comuns ao grupo ou atuando de forma complementar. Normalmente, as redes horizontais são formadas por empresas concorrentes, visando à obtenção conjunta de benefícios como aprendizagem, legitimação, status e benefícios econômicos (PODOLNY; PAGE, 1998). Nesse grupo, surgem formas alternativas de organização, como os consórcios de empresas que passam a absorver as fases iniciais e finais da cadeia de valor (desenvolvimento de produtos e distribuição/marca/exportações), enquanto as empresas componentes se concentram na produção.

O conceito de organização em rede, apesar de ter ganho força e nova configuração na economia informacional, vem sendo adotado há muito nas sociedades do Leste asiático, estando inserido em sua cultura e instituições. Mas a sua configuração dinâmica surge na segunda metade do século XX, sob o impulso do Estado desenvolvimentista que orienta o desenvolvimento dos negócios e das redes e os apóia financeiramente com base em certas regras disciplinares. É nesse sentido que essas economias vêm registrando uma forte vantagem comparativa na concorrência global, por sua rápida adaptação à lógica do paradigma tecnológico, determinando até alterações profundas no equilíbrio do comércio internacional e da acumulação do capital a seu favor.

Entre os estudos identificados na literatura sobre redes organizacionais devem ser ressaltados aqueles que adotam os seguintes modelos básicos de análise: os que levam em conta a atividade econômica das empresas associadas em rede para identificar oportunidades de agregação e envolvimento organizacional, destacando como fator de motivação a economia dos custos de transação; os que se baseiam nas relações existentes entre os atores envolvidos no processo de formação e desenvolvimento da rede, destacando a sua gestão interna e a definição dos papéis organizacionais; e, finalmente, os que abordam as estratégias organizacionais desenvolvidas na rede, com ênfase nos padrões de complementaridade e especialização das empresas que a compõem em seus processos e produtos específicos.

Segundo Mulgan (1991), as redes são ativadas para ganhar posições e melhorar a comunicação. Em essência, as redes vêm amplificar a capacidade essencial que unidades ou agentes devem possuir para gerar, processar e aplicar de forma eficiente a informação baseada em conhecimento para garantirem sua produtividade e competitividade. Elas representam a alternativa natural para tratar a impossibilidade das grandes empresas lidarem com a teia de alianças estratégicas, de processos de terceirização e com a descentralização em larga escala do processo decisório empresarial (MULGAN, 1991).

Os sistemas de rede e a filosofia da cooperação passaram a representar a alternativa mais efetiva para dividir custos e riscos e para acompanhar a dinâmica dos mercados através da coleta, geração e processamento de suas informações. Além disso, as redes controlam o ingresso nos mercados e criam, constantemente, novas oportunidades de negócios.

As redes que envolvem produção conjunta exigem elevados níveis de cooperação interorganizacional, para se superar conflitos que também ocorrem de modo simultâneo, sobretudo, nas estruturas com maior número de componentes. A cooperação, segundo Casarotto Filho e Pires (1999), pode adicionar valor aos produtos/serviços de redes de empresas, sob várias circunstâncias:

- ao se transferir à empresa gestora da rede as funções iniciais da cadeia produtiva, estariam sendo potencializados os aspectos de oportunidade, responsividade, melhoria de performance, redução de custos e riscos, agregação de valor para os clientes, reforço aos produtos/serviços existentes, melhoria do suprimento, da distribuição e aumento do poder de compra;

- alocando-se à rede as funções finais da cadeia, a tendência é de melhoria da imagem do produto/serviço, da cobertura do mercado, abertura de novos canais e a quebra de barreiras à entrada em novos negócios e novos mercados; 
- atribuindo-se a gestão dos negócios à rede, reforça-se a estratégia competitiva, possibilitando, ainda, a melhoria da gestão das pessoas, a aceleração da curva de aprendizado, a elevação do padrão de qualidade, o aumento das receitas e a redução dos custos e riscos da gestão e financeiros.

As evidências, então, comprovam que o mundo contemporâneo assiste à formação de um novo paradigma organizacional constituído dos seguintes elementos: propagação e aprimoramento do modelo de redes de empresas de diversas formas, atuando sobre diferentes contextos e culturas; presença de meios tecnológicos adequados ao desenvolvimento e manutenção das conexões entre as empresas nas redes; concorrência global exercendo pressão contínua por competitividade para atender à dinâmica dos mercados, exigindo flexibilidade; presença do estado coordenador/assessor, participando da construção de estratégias e incentivando as redes, seja na sua formação ou no seu aprimoramento; necessidade de equacionar o problema da produtividade do capital; e a cultura como elemento de ligação dos elementos dando consistência ao conjunto.

Mas, para que as redes de empresas de fato atinjam seus objetivos, é necessário garantir certos requisitos, considerados fatores críticos de seu sucesso:

- a atuação governamental mostra-se indispensável na criação de redes verticais e de redes horizontais de empresas. Tanto pela garantia de que haverá relações contratuais justas entre as grandes empresas e seus subcontratados, evitando que o modelo seja utilizado simplesmente para a redução de custos, quanto no fornecimento de apoio técnico na formação das redes, na criação de instituições de apoio e fomento aos pequenos empreendimentos;

- instituições de apoio podem oferecer apoio técnico e gerencial em caso de dificuldade de qualificação por parte das empresas componentes, além de contribuir para a geração de inovações e para a transferência de tecnologia e conhecimento;

- definição de objetivos convergentes entre os individuais das empresas participantes e os da rede, para evitar as estratégias de saída;

- o fator cultural possui importância significativa na formação das redes, sobretudo nas horizontais, onde há maior dependência do fator confiança entre os participantes e de regras preestabelecidas. $\mathrm{O}$ fator cultural, de fato, representa um dos elementos de resistência a mudanças nos processos e na estrutura organizacional. Nesse sentido, há que se prever formas de vencer as resistências. Segundo Ansoff (1993), essas formas de resistência podem ser classificadas em comportamental (ameaça às culturas e posições já conquistadas) e sistêmica (competição entre atividades operacionais e estratégicas cooperação $x$ autodeterminação e desenvolvimento independente) e apresentam, inclusive, reflexos em variáveis externas à organização, mas que influenciam, de certa maneira, os resultados e o equilíbrio da rede organizacional;

- a capacidade de definir relações entre as empresas segundo parâmetros de concorrência de mercado e avaliação de participação, de comportamento e resultado (competitividade);

- o respeito às peculiaridades locais e às exigências do mercado na estruturação e configuração das redes de empresas, visando adaptar-se às mudanças e conseguir resultados segundo o desenvolvimento do negócio central (manutenibilidade);

- o padrão equilibrado de interdependência entre as organizações, a fim de que estas possam se adequar melhor às demandas e proporcionar resultados duradouros (auto-regulabilidade). Esse atributo exige maiores níveis de confiabilidade e autonomia;

- o desenho dos interesses na rede é fundamental para prevenir a tendência à sua desagregação (integrabilidade);

- a liderança deve ser baseada no trabalho em equipe para resolução de conflitos e na solução de problemas; 
- as informações devem transitar por toda a rede; e

- a hierarquia deve ser encarada como um entre muitos meios para coordenar e controlar as ações por meio das pessoas, o conhecimento, o tempo e o espaço.

As mudanças no processo de gestão e estruturação da rede organizacional requerem, também, novas relações quanto à gestão do trabalho, visando maior participação e uma colaboração efetiva dos recursos humanos, exigindo, assim, das empresas, uma necessidade de adaptação da organização ao indivíduo e vice-versa (PERROW,1997).

Segundo Cardoso, Alvarez e Caulliraux (2002), o sucesso das redes está no alcance de melhores resultados globais para o conjunto de empresas, através da coordenação do trabalho e do aproveitamento sistêmico de recursos existentes nas empresas que as compõem, não no que gera de benefícios apenas para cada uma das empresas individualmente. Nesse sentido, uma rede em que a competitividade individual cresce, mas a custa de uma gradativa deterioração na qualidade dos relacionamentos, tende a gerar resultados negativos no futuro, donde se conclui que a qualidade dos vínculos da rede é tão ou mais relevante que exclusivamente o compartilhamento de recursos e funções.

Podem ocorrer turbulências nas organizações em rede caso a complexa organização de objetivos e funções individuais e do todo não sejam percebidas pelos gestores das empresas associadas. Diante da importância para a sobrevivência da rede, dos aspectos associados às relações entre as empresas que a compõem, Park (1996) propõe um modelo de análise de redes com base em dois enfoques:

- do controle e da gestão da rede - a partir da identificação das competências e dos processos de tomada de decisões interorganizacionais, da própria estrutura da rede e de como as empresas se interrelacionam; e

- da institucionalização da rede - através das formas das estruturas para execução dos papéis organizacionais, aí ressaltando os mecanismos de gestão (controles, comportamentos e posturas) voltados para as estruturas de mercado e para as formas como as empresas reagem às mudanças por este exigidas.

Sob o enfoque de controle e gestão, as redes devem ser analisadas na visão de Park (1996), considerando as seguintes variáveis: integrabilidade, que é a capacidade da rede de estabelecer relações interorganizacionais entre as empresas que a compõem segundo princípios de cooperação e de comprometimento mútuos, em função dos objetivos da rede; e auto-regulabilidade, que é a capacidade das empresas associadas à rede apresentarem maior adequação às demandas e de proporcionar resultados adequados e duradouros. Deve haver um grau satisfatório de interdependência entre as organizações, mantendo-se um bom nível de confiabilidade e autonomia.

Em relação à institucionalização da rede, as variáveis de análise a serem consideradas são: manutenibilidade - a capacidade da rede de se adequar às exigências do mercado e da rede organizacional, visando adaptar-se às mudanças e conseguir resultados segundo o desenvolvimento do negócio central; e competitividade - a capacidade da rede de definir relações entre as empresas segundo parâmetros de concorrência e de mercado.

Avaliar o sucesso de redes, na visão de alguns autores, significa medir o sucesso financeiro individual das empresas que a integram e da rede em termos globais; o impacto sobre a competitividade global do sistema; e seu resultado social, traduzido em benefícios ao desenvolvimento local. Já CEGLIE \& DINNI (1999), adotando o modelo NET (network evaluation tool), entende que o sucesso das redes deve ser medido através de fatores quantitativos relacionados à performance econômica dos componentes e do sistema, bem como de fatores qualitativos traduzidos pelos elementos: nível de coesão, flexibilidade da estrutura de organização interna, capacidade de análise estratégica, capacidade de planejamento estratégico, reestruturação da produção e capacidade de conexão com o ambiente institucional. Outros defendem que se os gestores das empresas da rede 
não perceberem os objetivos e funções individuais e sistêmicas da rede, poderá haver conflitos internos e vulnerabilização da rede, comprometendo os seus resultados.

A relação existente entre as empresas nas redes constitui objeto do modelo de análise de Park (1996), que leva em conta dois conjuntos de indicadores: aqueles relativos ao controle e gestão da rede (competências e processo de tomada de decisões) e aqueles referentes à institucionalização da rede (análise das estruturas formadas a partir da definição de papéis e responsabilidades).

\section{Os consórcios gaúchos como redes: formação e desenvolvimento}

Consórcios são estruturas organizacionais comuns no mundo contemporâneo, que podem assumir formas variadas e abranger distintas finalidades, tais como: formação ou valorização de determinado produto, valorização de marca, comercialização, agregação de qualidade e a escala para obtenção de recursos financeiros, entre outras. Três grupos de consórcios são comuns na literatura: o consórcio setorial, formado por empresas concorrentes e complementares que realizam um acordo para ampliar a competitividade dos seus membros pela difusão de informações e complementaridade produtiva; o territorial, que reúne empresas de todos os setores e atividades de um território, servindo à divulgação de informações e à promoção do conjunto de empresas e do próprio território; e o específico, que restringe sua atuação a um objetivo específico que pode ser, inclusive, temporal.

Essas estruturas vêm atuar, exatamente, nas etapas da cadeia de valor em que as empresas individualmente não têm competência para dominar. $\mathrm{O}$ que as pequenas empresas sempre fizeram, e bem, foi produzir com flexibilidade e administrar essa produção. À medida que o mundo dos negócios foi adquirindo complexidade, a cadeia de valor foi se expandindo e suas competências centrais, de produção, foram se tornando insuficientes para manter a competitividade. É aí que surgem as cooperações para compartilhar as funções iniciais e finais da cadeia de valor (CASAROTTO FILHO; PIRES, 1999).

De forma geral, são os seguintes os tipos de serviços que os consórcios devem oferecer às empresas consorciadas: distribuir dinamicamente informações sobre o mercado e oportunidades identificadas, individuais e coletivas; acompanhar a evolução da produtividade e qualidade da produção, como forma de garantir o mercado atual e permitir o acesso a novos mercados; adotar o estímulo ao uso de novas tecnologias como instrumento de ampliação das formas de aprendizagem e aumento da competitividade individual e coletiva; orientar as consorciadas sobre formas e fontes de financiamento para inovação e novos projetos; e promover a imagem do consórcio, territorialmente, através de suas características e vantagens competitivas.

A estrutura de organização sugerida por Casarotto Filho e Pires (1999) deve incorporar características como versatilidade, rápida capacidade de resposta à dinâmica do mercado, estrutura operacional mínima e poucos profissionais, porém, qualificados e com grande conhecimento das empresas participantes, do mercado, da tecnologia e dos serviços relacionados.

Os consórcios gaúchos são entes formados da reunião de empresas operadoras do transporte urbano de Porto Alegre.

Vale lembrar que a Região Metropolitana de Porto Alegre (RMPA) é a área com maior densidade populacional do estado do Rio Grande do Sul, concentrando 37\% (trinta e sete por cento) da população em 31 municípios. Nela encontram-se 10 dos 17 municípios do estado com mais de 100 mil habitantes. O município de Porto Alegre, no censo demográfico de 2000, apresentava população total de 1.360 .590 habitantes e uma taxa de crescimento anual de $0,94 \%$, a terceira menor de toda a Grande Porto Alegre.

O município de Porto Alegre é servido por transporte por ônibus do tipo urbano, do tipo metropolitano, por uma linha de metrô (Trensurb) e por serviço de táxi-lotação regulamentado e realizado por microônibus. O transporte por ônibus urbano hoje é realizado por 14 (quatorze) empresas privadas reunidas em três consórcios (Conorte, Unibus e STS) e uma empresa pública, a Carris Porto Alegrense, tida como referência nacional nesse 
segmento, que funciona como um quarto consórcio, já pertenceu a uma companhia americana entre 1928 e 1954 e hoje é uma empresa de economia mista com controle acionário da Prefeitura Municipal de Porto Alegre.

No final da década de 1970, foi desenvolvido o Plano Diretor de Transportes da Região Metropolitana de Porto Alegre (PLANMET/PA), objetivando a implantação de infra-estrutura que priorize a circulação do transporte coletivo, com vistas a segregar automóveis e ônibus do transporte público, para que este atingisse maiores níveis de produtividade.

Nessa época, o sistema de transporte de Porto Alegre era basicamente radial concêntrico, em forma de leque, com convergência das linhas urbanas e interurbanas para a área central da cidade, sobrecarga de tráfego e superposição de linhas urbanas, principalmente, nos eixos das avenidas Farrapos, Assis Brasil, Baltazar de Oliveira Garcia, Bento Gonçalves, Protásio Alves e João Pessoa. O mesmo ocorria com relação às linhas metropolitanas e urbanas nas radiais mais significativas, a BR116 (trecho norte) e as avenidas Assis Brasil e Bento Gonçalves, tornando-as inacessíveis em horários de pico de oferta. O sistema de ônibus da Grande Porto Alegre transportava cerca de 487.000 passageiros nos dias úteis, sendo 328.000 no transporte urbano do município.

Os corredores previstos pelo PLANMET foram implantados no período de 1979 a 1981, sendo o corredor da Farrapos o derradeiro a ser implantado. O projeto do Trensurb foi implantado em 1985 e possibilitava a ligação de Porto Alegre ao município de Sapucaia, passando por Canoas e Otero.

Mesmo com a implantação dos corredores, nos dias subseqüentes à inauguração do corredor da Assis Brasil havia (entre metropolitanos e urbanos) 320 ônibus para passarem em uma hora no pico da manhã (6h30min7h30min), o que o corredor não comportou. Diante da sobrecarga nos corredores, as maiores linhas urbanas foram desdobradas em dois grupos; uma parte continuava pela Assis Brasil até o terminal da Cairu e a outra, pela Sertório, que ainda não era corredor, para atender à área da Farrapos e o Centro da cidade. Houve muita resistência das operadoras, visto que o desvio para a Sertório não representava um pólo de atração tão importante. O novo corredor não teve sucesso, mesmo com a criação das linhas transversais de ligação com o corredor da Bento Gonçalves.

Por volta de 1986, esgotaram-se as possibilidades de se solucionar o problema de capacidade e de compatibilização operacional de linhas urbanas e metropolitanas em comboio ordenado na mesma faixa exclusiva. Havia um forte conflito entre as empresas na competição pelos passageiros no corredor e para entrada favorável no comboio. O tempo das viagens aumentou consideravelmente e a produtividade só caía, elevando os custos do sistema de transporte urbano. Ainda que houvesse alguma restrição contratual para o embarque de passageiros no sentido municípios - centro de Porto Alegre e mesmo levando em conta o fato das tarifas metropolitanas serem mais elevadas, havia o compartilhamento do corredor pelos ônibus metropolitanos e urbanos agravando o problema da capacidade viária.

Alguns anos após a implantação do Trensurb, em 1988, já ocorria uma primeira idéia de formação de modelo informal de administração tipo consórcio em Porto Alegre, entre as empresas Sopal e Nortran.

Outro fator que favoreceu a formação dos consórcios foi a necessidade de organizar o acesso e reduzir a quantidade de ônibus urbanos e metropolitanos no corredor da Assis Brasil, o que, entretanto, esbarrava na exigência dos empresários de garantia de receita. Como garantir a receita mesmo com a redução da frota era a grande questão.

Em princípio, essas idéias que timidamente apontavam para a formação de estruturas de consórcios não foram adotadas. Nessa época, em 1989, o Partido dos Trabalhadores iniciava sua gestão na prefeitura de Porto Alegre com a eleição de Olívio Dutra, e a nova administração foi além, decidindo intervir no sistema de transporte. Foram 16 anos em que Porto Alegre esteve sob o comando do PT, através das gestões de Tarso Genro (1992-95 e 2000-02), Raul Pont (1996-99) e João Verle (2002-04). 
A intervenção foi concluída em 1991, quando a empresa Sopal foi devolvida à iniciativa privada, já dividida em duas outras operadoras, a Fênix e a Vianorte. A difícil situação dessas empresas estimulou um acordo entre todas as operadoras do transporte público da zona norte, Vianorte, Fênix e Nortran, para a formação de um novo modelo de administração consorciada, o que aconteceu em março de 1993, tendo como controladora, em termos operacionais, a Vianorte Serviços.

A estruturação do modelo de consórcio em Porto Alegre veio para substituir práticas de concorrência danosas entre permissionários do serviço por práticas de convergência e compatibilização de esforços. Seu objetivo foi também atender aos requisitos para eliminação de serviços concorrenciais que oneram o sistema, através do estímulo à racionalização operacional e à economia de escala, bem como pela promoção de uma remuneração da produção baseada na quantidade e na qualidade dos serviços prestados.

Note-se que no próprio PLANMET já havia referência à necessidade de se reduzir a competição nos corredores quando já se indicava que a operação deveria ser restrita a uma concessionária.

O modelo físico-operacional do sistema de transporte, à época da formação do primeiro consórcio, era do tipo radial-concêntrico, com algumas linhas transversais e a competição entre as empresas ocorrendo nos limites entre essas regiões ou bairros, no que são denominados radiais ou corredores, onde operavam várias empresas. O sistema transversal era totalmente operado pela empresa pública municipal, em caráter de monopólio.

O sistema apresentava várias deformações, como a competição excessiva nos corredores e a garantia de mercados cativos, além de desajustes entre os subsistemas radial e transversal e entre a oferta e a demanda do sistema, gerando deseconomias e aumento de custos do sistema, onerando a tarifa. Não havia integração tarifária; o que obrigava os usuários a arcarem com nova tarifa a cada transbordo.

Para que se implantasse o modelo de operação consorciada, algumas condições tiveram que ser estabelecidas: centralização da receita; redistribuição da receita pelo serviço realizado com base em padrões de eficiência empresarial; estabelecimento do princípio da isonomia, mesma remuneração por serviço prestado de forma idêntica; e desaparecimento da figura do mercado cativo para cada empresa individualmente.

Os consórcios de Porto Alegre derivam de uma divisão das áreas de operação em bacias. Utilizando critérios geográficos, foram constituídas três bacias que terminaram dando origem aos consórcios operacionais atuais, o Unibus, o STS e o Conorte. A empresa pública Carris foi mantida, operando linhas rádio-transversais entre os consórcios. O critério de divisão em bacias é reconhecido como um instrumento de disciplinamento do mercado das empresas privadas. A operadora pública teve seu mercado estabelecido por critérios geográficos e funcionais.

A primeira função atribuída ao consórcio ou empresa controladora foi a de fiscalizar a operação, mantendo a soltura dos ônibus sob a responsabilidade de cada empresa "consorciada". Em seguida, deu-se a unificação da soltura dos veículos, em virtude dos conflitos que passaram a existir entre os operadores das garagens e a fiscalização do consórcio. Implantou-se, mais adiante, a centralização da programação de linhas (horários e itinerários) e a representação unificada das empresas junto ao poder concedente e demais órgãos públicos envolvidos com a gestão do transporte.

O primeiro consórcio, o Conorte, estrutura-se mesmo a partir de 1995, entre as empresas Sopal e Nortran. Em 1996, foi criado o consórcio STS (Sistema Transportador Sul), já por orientação da Secretaria Municipal de Transportes, formado pelas empresas da zona sul de Porto Alegre.

Em agosto de 1997 é criado o terceiro consórcio, o Unibus (Consórcio União da Bacia Urbana Sudeste Leste). Com a formação do último consórcio, a Secretaria Municipal de Transportes formaliza, através das resoluções $\mathrm{n}^{\mathrm{os}} 003$ e 007/97, a organização das empresas permissionárias em consórcios operacionais, instituindo um único centro de "imputação de custos e receitas". 
Os contratos de cada consórcio têm, no geral, estrutura semelhante e estabelecem, além das regras de convivência interna e de colaboração interempresarial, a divisão de mercado e os critérios econômicos decorrentes dessa divisão, inclusive os percentuais de cada um na receita do sistema de transportes, que constituem a denominada matriz de partilha. Os consórcios estabelecem padrões de serviço a serem seguidos pelas consorciadas que, caso não os atinjam, terão a parte de sua produção não realizada, coberta por outras empresas do consórcio que ficarão com crédito de serviço a ser compensado posteriormente.

Ao aderirem aos consórcios, as empresas operadoras se transformam em fornecedoras de serviço e de mão-deobra, mantendo a sua identidade, autonomia e a propriedade dos ativos (frota e garagem), além da relação trabalhista com os seus empregados. Nessa configuração, os equipamentos públicos da rede de transportes são mantidos sob a responsabilidade do poder público. Todo o gerenciamento operacional é responsabilidade do consórcio.

Com a formação dos consórcios, mudaram também alguns conceitos: as linhas antes pertencentes a cada empresa operadora passam a "pertencer" ao consórcio; as negociações com o poder concedente deixam de ser realizadas pelas empresas, passando a ser comandadas pelo consórcio; e cria-se o conceito de quilometragem qualificada.

O modelo institucional ainda não se mostra de forma muito clara. Fala-se muito em parcerias entre o poder público e os delegatários e de uma maior autonomia dos consórcios no planejamento do serviço, embora não se tenha uma regulamentação aprovada. Não há ainda qualquer contrato entre os consórcios e a prefeitura. Foi firmado um acordo tácito para um período de transição em que os operadores existentes continuariam operando o sistema sob o regime da permissão e realizando investimentos programados. Inicialmente, manteve-se o modelo tradicional de administração e exploração do serviço, para em seguida evoluir-se para imputar maior autonomia na atuação das operadoras nas áreas de planejamento e controle da operação do serviço.

Após esse período de transição, a prefeitura deverá licitar as bacias e substituir o modelo de permissão pelo de concessão não onerosa do serviço, no qual se evoluirá para a participação conjunta entre gestor público e concessionários na elaboração do planejamento do serviço e na gestão da operação. A idéia é a de que na licitação, garagem e veículos sejam de responsabilidade do operador e a infra-estrutura, do poder público, exceto em relação à construção de corredores ou terminais.

\section{Conclusões}

A experiência de gestão compartilhada do transporte urbano em Porto Alegre não nasceu de forma organizada, planejada, tampouco tendo como base um modelo científico testado e bem-sucedido. Foi um movimento casuístico contextual, para tentar solucionar uma questão localizada de competição predatória nos corredores que trouxe ociosidades ao sistema, e que, se persistisse, traria mais deseconomias e poderia levar ao colapso do sistema, já que a oferta e custos aumentariam enquanto a demanda só decresceria.

Esse problema afetava empresários - que viam sua lucratividade e sobrevivência em risco - e o poder público - que numa ameaça de colapso teria de responder pela continuidade da prestação do serviço -, além de usuários e trabalhadores. Os usuários, porque o aumento dos custos, sem repasse correspondente à tarifa-preço, comprometia a qualidade do serviço e por menor que fosse esse repasse, ampliava a parcela dos excluídos sem condições de arcar com os reajustes tarifários. Os trabalhadores, por causa das condições de trabalho adversas, resultantes da acirrada competição por passageiros nas ruas e das ameaças de desemprego e de perda salarial.

Todos os entrevistados reconheceram essa situação, e alguns até admitiram que houve uma certa pressão do poder público para que os últimos consórcios se formassem, porque isso representava um pacto e uma facilitação das relações entre a prefeitura e os permissionários do serviço. A prefeitura, acenando com uma flexibilização maior na gestão do serviço sob o ponto de vista do planejamento operacional, da remuneração e da gradativa eliminação da compensação tarifária. Os empresários, com a intermediação do entendimento entre 
eles e com a disposição de investir em melhoria da qualidade do serviço, desde que contida a expansão da oferta e dos custos e garantida a justa remuneração pelo serviço.

Os consórcios foram parte da estratégia política e de negociação que contou, ainda, com a revisão do modelo físico-operacional, econômico, institucional e de remuneração, que culminou com uma expressiva remodelagem do sistema de transporte público de Porto Alegre. Facilitaram a promoção do entendimento dos empresários, a redução das resistências e a elevação do nível de operação das empresas através da adoção de padrão referencial e aceleração da curva de aprendizado entre as suas consorciadas.

Apesar de não terem sido formados intencionalmente como modelo de organização em rede, os consórcios gaúchos apresentam algumas características próprias desse tipo de arranjo organizacional, apesar de incompleto e, portanto, sem condição de usufruir dos benefícios plenos dele advindos. O objetivo básico foi o alcance de benefícios econômicos, mas outros benefícios vieram, sobretudo, como resultado do entendimento entre eles. Mas esse entendimento poderia ter sido alcançado de outra forma, como por exemplo, na organização de um só consórcio, ao invés de três.

Os fatores motivadores para a formação dos consórcios gaúchos não foram, então, os típicos para a formação das redes: o desejo de cooperar, a cultura da confiança, a necessidade de buscar competências específicas e a definição conjunta de objetivos próprios de cada organização e da rede como um todo. Muitos entraram nos consórcios obrigados e desconfiados e foram se acomodando com o tempo.

Observa-se, assim, que os consórcios gaúchos são uma representação ainda imatura do modelo de organizações em rede, mais precisamente do modelo de rede horizontal, não estando prontos a usufruir todas as potenciais vantagens decorrentes desse tipo de configuração organizacional. Em primeiro lugar, porque embora se pregue a diluição do risco e o compartilhamento de recursos para evitar duplicidade onerosa de esforço, o modelo gaúcho parece indicar inicialmente, não uma intenção primordial de criar um instrumento de cooperação efetivo para ampliar a competitividade e responder mais adequadamente à dinâmica do mercado, mas um meio para reduzir a competição no sistema de transporte público, partindo-se da constatação de que esse mercado e sua receita são limitados. Segundo, apenas um dos objetivos para a formação de redes parece ter mobilizado a formação dos consórcios gaúchos; ou seja, o alcance de benefícios econômicos. Parece haver uma forte intenção de reduzir custos, dividir amigavelmente esse mercado já oligopolizado e fugir da regulamentação excessiva do poder concedente. Com os consórcios e estabelecidas as regras do jogo e a padronização do serviço, retira-se o medo do competidor formal entrar no mercado de forma velada e minimiza-se a atuação das câmaras de compensação, que conseguiram estabelecer uma unânime insatisfação por parte do empresariado.

Alguns dos fatores motivadores da formação de redes, como o desejo de cooperar e a cultura da confiança, são elementos complexos na realidade do segmento de transportes, cujos interesses individuais de sobrevivência e crescimento empresarial são fortes. Há, naturalmente, uma certa desconfiança entre eles quanto a interesses individuais e coletivos, e isso tende a repercutir nos resultados dos consórcios. Mas isso não significa que também não haja, por parte dos empresários gaúchos, um desejo de reduzir os seus conflitos e jogos de poder, de amenizar a disputa pelos passageiros e pela ampliação de sua participação de mercado.

A expansão contínua e no, mais das vezes, desarticulada, do tecido urbano, torna o transporte urbano de passageiros uma atividade extremamente dinâmica em que os atendimentos são sempre urgentes e prioritários, até por conta da pressão social. Os consórcios gaúchos aparentam não disporem de flexibilidade adequada, típica das redes maduras, para dar tratamento coerente a essas questões, já que adotam estrutura organizacional verticalizada e conservadora, além de regras rígidas de adesão, saída e convivência. Outro aspecto importante é que as empresas componentes também não indicam uma mudança organizacional significativa ao aderirem ao consórcio.

Outra questão importante dos consórcios gaúchos, que pode comprometer a alcance dos benefícios das organizações em rede, é a pequena escala de utilização da tecnologia como instrumento de geração de conhecimentos e processamento de informações, de alcance de uma maior produtividade. 
Quanto às similaridades com os modelos planejados de organizações em rede, identifica-se nos consórcios gaúchos que:

- há um razoável grau de aderência dos objetivos individuais das empresas consorciadas aos do consórcio como um todo (coerência);

- foram estabelecidos mecanismos concretos que resultaram em definição de comportamentos integrados, vantagens individuais e coletivas, clareza na tomada de decisões, papéis das empresas consorciadas e formação de padrão;

- houve uma obtenção conjunta de certos benefícios como aprendizagem, legitimação e status, além dos benefícios econômicos não mencionados;

- houve divisão de riscos e custos com a sua formação, ainda mais pelo fato da receita ser única e proveniente da coleta das tarifas; $\mathrm{e}$

- foi reforçada a estratégia competitiva ao atribuir-se a gestão dos negócios aos consórcios, possibilitando alguma melhoria na gestão do pessoal de operação, a aceleração da curva de aprendizado e a elevação do padrão de qualidade, sobretudo, quanto à operação (frota e cumprimento de horários).

Apesar de todas essas similaridades, alguns fatores críticos de sucesso e que são requisitos para a manutenção das organizações em rede precisam ser equacionados pelos consórcios gaúchos. Os consórcios gaúchos não dispõem de flexibilidade, como se viu, para atender a novas demandas que surgem dinamicamente nesse setor, abrindo espaço para que a operadora pública cresça e as atenda. No entanto, essa capacidade de remanejamento de oferta de certas áreas para novas áreas é finita. Depois de racionalizado o sistema, essas novas demandas terão que ser atendidas com ampliação de oferta, sob pena de comprometimento da sustentabilidade do modelo.

Além disso, a inovação não tem sido um elemento presente nas estruturas de consórcio. Percebe-se certa acomodação e algum descrédito, no sentido de que essa estrutura possa evoluir para absorver outras funções que gerem maior economia de densidade porque a cultura das empresas não permite.

Os consórcios ficaram restritos à atividade operacional (operação, controle e fiscalização), e as empresas, ao aderirem, não mudaram suas estruturas internas de organização, embora tenham aprendido com a padronização e com as outras empresas consorciadas. Mas para assegurar essa adaptabilidade crescente e fazer o consórcio amadurecer, a empresa tem que se horizontalizar, também se tornar uma rede, descentralizando a tomada de decisões e absorvendo o conceito de unidades de negócios.

A atuação governamental, fator inestimável para legitimação de todo o modelo, precisa ser estabilizada. Ainda há desconfiança por parte de gestor atual da EPTC quanto à validade e durabilidade dos consórcios, como também, por parte das empresas quanto ao processo de tomada de decisões em um dos consórcios.

Há, ainda, uma questão jurídica a ser equacionada. Esses consórcios não foram escolhidos através de processo licitatório, conforme exige o artigo 175 da Constituição Federal e a Lei no 8.987/95. Ao que tudo indica, os atuais consórcios detêm o direito de exploração por determinação de decreto municipal que garante a continuidade da exploração até que sejam ultimados estudos tendentes a uma global reestruturação dos serviços de transporte coletivo. Nesse sentido, tanto o Ministério Público Estadual quanto empresas que querem participar da exploração do serviço público questionam judicialmente as infinitas prorrogações dessas permissões/concessões. Esse fator traz grave ameaça à continuidade dos consórcios, já que por determinação constitucional e infraconstitucional, a prestação de serviço público, sob o regime de concessão ou permissão, sempre se dá através de licitação.

O sistema de transporte público de Porto Alegre impõe ainda, a uma razoável parcela de seus usuários que não são atendidos por uma só linha, o peso de uma segunda tarifa, e há resistências à implantação da integração tarifária que poderia vir com a bilhetagem eletrônica, criando, de fato, uma rede metropolitana de transportes 
com todos os modais associados. O consórcio, da maneira como foi formado em Porto Alegre, constitui um modelo de organização ainda carente de aperfeiçoamento que, embora tenha auxiliado na melhoria da conjuntura local do transporte público, ao lado de outras ações implementadas, não pode ser adotado indiscriminadamente em qualquer município com características físicas, operacionais, institucionais, econômicas e políticas particulares.

Os princípios que regem as verdadeiras organizações em redes horizontais, esses sim, podem servir como referência para buscar estruturas que sejam mais inovadoras e flexíveis, capazes de responder adequadamente à dinâmica do mercado de transportes, mas sempre conscientes de que as soluções duradouras têm que ser buscadas através da elaboração e execução de políticas nacional e local integradas de mobilidade urbana, priorizando efetivamente o transporte coletivo como elemento de inclusão social. 


\section{Referências}

ALTER, C.; HAGE, J. Organizations working together. Newbury Park, CA: Sage, 1993.

ANSOFF, H. I. Gestão da mudança estratégica. IN: Implantando a administração estratégica. São Paulo: Atlas, 1993, p.461-529.

CANDIDO, G. A formação de redes interorganizacionais como mecanismo para criação de vantagem competitiva e para promoção do desenvolvimento regional: o papel do Estado e das políticas públicas globais neste cenário. Disponível em: <www.ch.ufcg.edu.br/gegit>. Acesso em: 18 fev. 2005.

CANDIDO, G.; ABREU, A. Os conceitos de redes e as relações interorganizacionais: um estudo exploratório. In: Anais Enanpad, 24., 2000, Florianópolis.

CARDOSO. V; ALVAREZ, R.; CAULLIRAUX, A. Gestão de competências em redes de organizações: discussões técnicas e metodologias acerca da problemática envolvida em projetos de avaliação. In: Anais Enanpad, 26., 2002, Salvador.

CASAROTTO FILHO, N. \& PIRES, L.H. Redes de pequenas e médias empresas e desenvolvimento local. Estratégias para a conquista da competitividade global com base na experiência italiana. São Paulo: Atlas, 1999.

CASTELLS, M. A sociedade em rede - a era da informação: economia, sociedade e cultura. São Paulo: Paz e Terra, 1999. v.1.

CEGLIE, G.; DINI, M. SME cluster and network development in developing countries: the experience of Unido. [S.I.]: United Nations Industrial Development Organization (Unido), 1999.

GRANDORI, A; SODA, G. Inter-firm networks: antecedents. Mechanisms and forms. Organization Studies, v. 16, n. 2, 1995.

MULGAN, G. Communication and control: networks and the new economies of communication. New York: Guilford Press, 1991.

PARK, S. H. Management an interorganization network: a framework of the institutional mechanism for network control. IN: Organization Studies. 1996, 17/5, p.795-824.

PODOLNY, J.; PAGE, K. Networks forms of organization. Annual Reviews Sociological, n.24, p.57-76, 1998.

PERROW, C. Small-firms networks.. IN: Networks and organizations. Boston: Harvard Business, 1997.

THORELLI, H.. Networks: between markets and hierarchies. IN: Strategic Management Journal. 1986, 7, p.37-51. 